\title{
CARCINOMA DE CÉLULAS RENAIS EM RIM TRANSPLANTADO: RELATO DE CASO E REVISÃO DA LITERATURA
}

\author{
Renal cell carcinoma in a transplanted kidney: case report and literature review
}

\author{
Fernando Korkes', Luiz Renato Montez Guidoni', Alvaro Alexandre Dias Bosco², Roni de Carvalho Fernandes ${ }^{3}$, \\ Marília Germanos de Castro 4 , Moacyr Fucs ${ }^{3}$, Marjo Deninson Cardenuto Perez ${ }^{5}$
}

\begin{abstract}
RESUMO
Introduçãoeodjetivo: A doença renal cística adqui rida tem sido relatada em rins de pacientes com doença renal terminal sem tratamento, tratados com diálise ou que foram submetidos a transplante renal. A incidência de tumor renal em pacientes com doença renal cística adqui rida submetidos à diál ise é el evada. Recentemente, foram relatados casos de carcinoma de células renais ocorrendo nos rins primitivos com doença renal cística adqui rida de pacientes submetidos a transplante. 0 presente relato tem como objetivo descrever mais um caso de carcinoma renal em enxerto renal. MétodoeRéatodo Caso: R elatamos um caso de carcinoma de células renais ocorrendo após 14 anos (169 meses) de transplante de doador vivo, no aloenxerto com doença renal cística adquirida, após ter evoluído com rejeição, tendo sido tratado com sucesso com a nef rectomia do enxerto. Conclusões: Pacientes submetidos a transplantes têm maior incidência de malignidade, quando comparados com a população geral. Incluindo este relato, são descritos 24 casos de neoplasias renais de novo em aloenxertos renais e, até onde vai nosso conhecimento, é o tercei ro caso de carcinoma de células renais associado a doença renal cística adquirida em aloenxerto renal, e o primeiro da literatura nacional.
\end{abstract}

Descritores: Transplante renal; Transplante; N eoplasias Renais; Ciclosporina; Complicações Pós-O peratórias; Nefropatias Policísticas

\footnotetext{
Grau acadêmico:

1. Médico Residente da Disciplina de Urologia da Santa Casa de São Paulo.

2. Médico Residente do Departamento de Cirurgia da Santa Casa de São Paulo.

3. Professor Assistente da Disciplina de Urologia da Santa Casa de São Paulo.

4. Professora Assistente do Departamento de Anatomia Patológica da Faculdade de Ciências Médicas da Santa Casa de São Paulo.

5. Chefe da Disciplina de Urologia da Santa Casa de São Paulo.
}

Instituição:

Disciplina de Urologia, Faculdade de Ciências Médicas da Santa Casa de São Paulo, São Paulo, SP, Brasil.

Correspondência:

Fernando Korkes

Rua Pirapora, 167 - CEP 04008-060 - São Paulo - SP - Brasil

E-mail: fkorkes@terra.com.br

Fone: 551138842233

Recebido em: 15/09/2005

Aceito em: 10/10/2005

\section{INTRODUÇÃO}

0 desenvolvimento de carcinoma de células renais (CCR) após o transplante renal tem sido relatado, mas a maioria das neoplasias acontece nos rins primitivos. 0 desenvolvimento de CCR de novo em um aloenxerto renal não é um relato freqüente. A maioria dos casos relatados ocorreu em aloenxertos de doadores falecidos em rins funcionantes.

Relatamos um caso de desenvolvimento deCCR em um aloenxerto renal (após rejeição) de doador vivo com doença renal cística adquirida (DRCA), 14 anos (169 meses) após o transplante.

\section{RELATO DE CASO}

Um homem de 27 anos de idade foi submetido a um transplante renal de doador vivo, haploidêntico, (recebido da sua irmã de 31 anos de idade), em setembro de 1990, para tratamento de insuficiência renal secundária à hipertensão arterial. 0 tratamento imunossupressor incluiu ciclosporina e prednisona.

Ocorreu nefropatia crônica do enxerto e rejeição 14 anos após 0 transplante, apresentando-se com aumento dos níveis de creatinina sérica para $4.6 \mathrm{mg} / \mathrm{dl}$, sendo realizada uma ultrassonografia para avaliação. Esta demonstrou vários cistos renais B osniak I, e uma imagem cística hipoecóica regular de 4,5cm, contendo uma área 
sólida sem fluxo sangüíneo. Foi realizada biópsia e o exame de congelação do espécime demonstrou apenas nefropatia crônica do aloenxerto. A chados histopatológicos posteriores demonstraram um padrão não usual de CCR. Foi realizada então nefrectomia do enxerto, uma vez que a função renal encontrava-se deteriorada e a terapia imunossupressora foi descontinuada (figura 1). A avaliação anátomo-patológica foi consistente com transformações císticas e carcinoma de células renais multifocal (figura 2). A recuperação

Figura 1. Aspecto macroscópico do rim transplantado multicístico, com lesões de 0.5 a $3.0 \mathrm{~cm}$, algumas com parede irregular e com carcinoma multifocal.

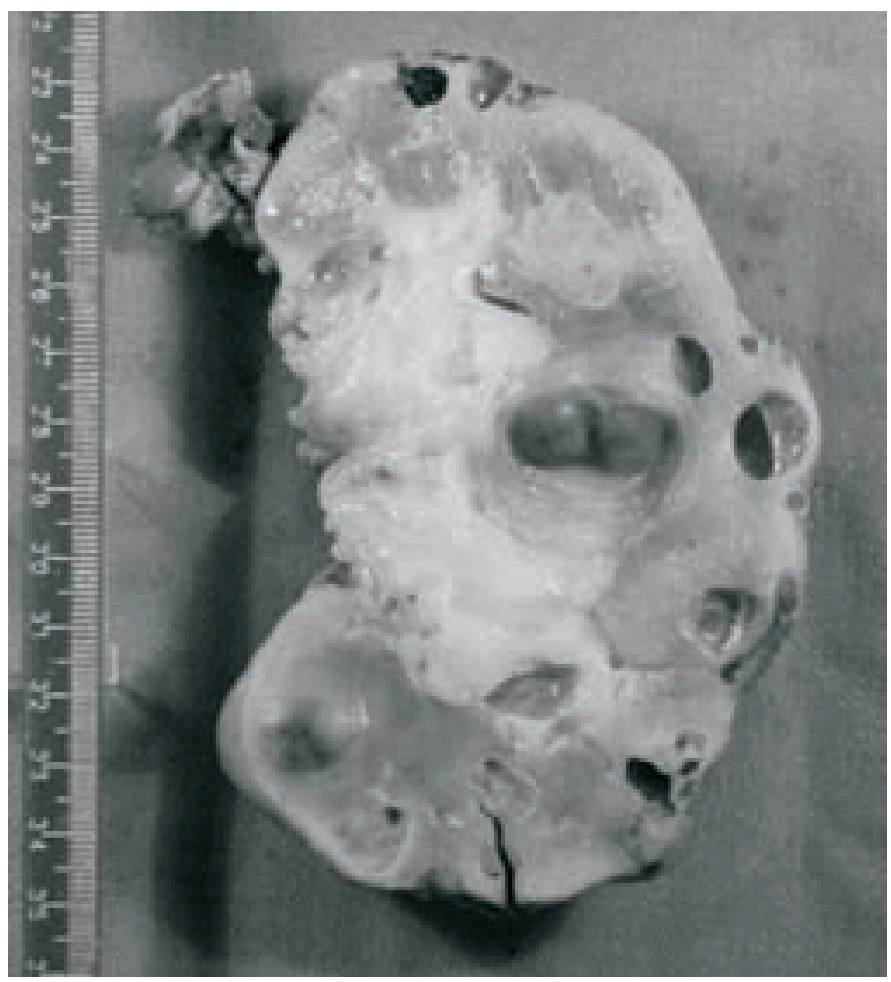

Figura 2. A. Exame histopatológico demonstra o CCR na parede do cisto (x100); B. Estruturas tubulares entre o estroma fibroso. (x100); C. Detalhe demonstra carcinoma de células claras (Hematoxilina-eosina 400x).

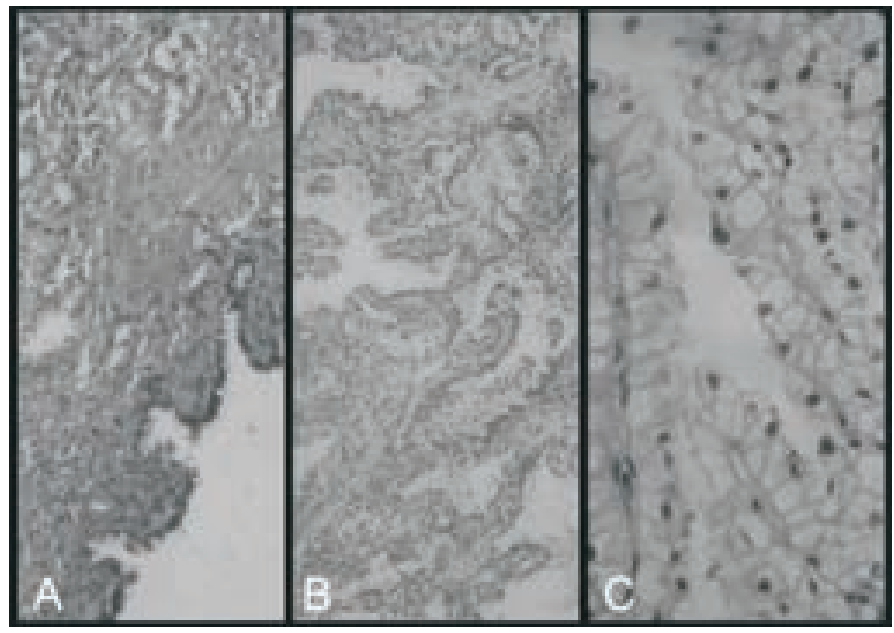

do paciente transcorreu sem intercorrências, sendo que o paciente iniciou hemodiálise no primeiro dia pós-operatório. Permanece em hemodiálise sem evidências de recorrência local ou de doença metastática, 14 meses após a cirurgia. Não havia lesões expansivas envolvendo os rins primitivos. Investigações aprofundadas não demostraram doença metastática.

Avaliações subseqüentes junto à doadora não demonstraram uma história familiar de tumores renais ou fatores de risco significativos para o desenvolvimento de malignidades. Aval iações ultrassonográficas do rim que permaneceu na doadora não evidenciaram cistos ou lesões sólidas.

\section{DISCUSSÃO}

Neoplasias somam aproximadamente 2,3\% das mortes em pacientes receptores de transplantes renais. ${ }^{1} 0$ carcinoma de células renais compreende 2,3\% de todas as neoplasias da população em geral, sendo mais comum em receptores de aloenxertos, os quais constituem $4,8 \%$ de todas as neoplasias. ${ }^{2}$ Tumores renais podem se desenvolver de novo nos receptores de enxerto renal ou nos rins primitivos, além de poderem ser provenientes dos doadores. ${ }^{3}$

Existem 24 casos de carcinoma em aloenxertos renais na literatura (MEDLINE 1966-2005), e 45 casos descritos no Cincinnati Transplant Tumor Registry. ${ }^{4} \mathrm{~A}$ Iguns destes, no entanto, podem ser decorrentes da transmissão da doença pelo doador, ocorrendo logo após o transplante. ${ }^{3}$

A DRCA tem sido relatada em rins de pacientes que se submetem a hemodiálise crônica, em pacientes com uremia que não são tratados com hemodiálise, em rins primitivos de receptores de transplantes renais e em aloenxertos associados à rejeição crônica. ${ }^{5} \mathrm{~N}$ o nosso paciente, a DRCA desenvolveu-se no enxerto renal, assim como é descrito em pacientes com uremia que não são tratados com hemodiálise.

A DRCA é um fator de risco bem estabelecido para o CCR. O bservase incidência de 5-19\% de CCR em pacientes em hemodiálise com DRCA.${ }^{5}$ Entretanto, na maior parte dos casos há um potencial de malignidade baixo dos carcinomas de células renais. ${ }^{5}$

Vários casos de CCR em rins primitivos com DRCA de pacientes submetidos a transplantes já foram relatados. ${ }^{6} \mathrm{M}$ as, dos 24 casos de CCR identificados em enxertos renais encontrados na literatura, grande parte apresentava preservação da função do enxerto e apenas dois possuíam DRCA $.7,8$ Como nesses dois casos, o nosso paciente apresentou-se com padrão cístico do CCR. Nos outros casos, diferentemente, foi predominante a lesão sólida. ${ }^{2,4,9} \mathrm{~A}$ maioria dos casos também foi encontrada em enxertos de doadores falecidos, sendo que apenas quatro deles eram relatos de enxerto de doadores vivos. ${ }^{4,10}$

Curiosamente, em todos os relatos de caso, a ciclosporina foi usada como terapia imunossupressora, enquanto a azatioprina, os corticosteróides e outras drogas foram usados em apenas alguns. ${ }^{4,7,8,9,11} \mathrm{~A}$ associação da ciclosporina e a DRCA nos rins primitivos foi relatada. ${ }^{12} \mathrm{Um}$ aumento de $8 \%$ a $57 \%$ na incidência da DRCA nos rins primitivos foi relatado em transplantados que receberam ciclosporina. ${ }^{12} \mathrm{No}$ entanto, outros estudos concluíram que não há evidências de aumento na taxa de neoplasia de novo com a ciclosporina, sugerindo que somente pelo fato de causar uma 
profunda imunossupressão poderia levar ao desenvolvimento de neoplasias em receptores de transplantes, por impedir os mecanismos do hospedeiro de identificar e destruir as células malignas. ${ }^{13}$

No que se refere ao tipo histológico, lesões simples ou multifocais foram observadas e diferentes subtipos de CCR foram relatados, como um caso de carcinoma de células escamosas. Um padrão comum observado em todos os casos foi a classificação como tumores de baixo grau. $24,4,7,8,9,11$ Entre alguns dos relatos de caso, técnicas de hibridização foram real izadas e demonstraram a origem dos tumores como sendo de genes dos doadores. ${ }^{2,7,14}$

0 tratamento do CCR em um rim transplantado, usualmente compreendea nefrectomia do transplanteea interrupção daterapêutica imunossupressora. Esse regime pode resultar na remissão completa, inclusive de pequenas metástases pulmonares.8 $\mathrm{N}$ ão há relatos de recorrência após o tratamento do CCR em um enxerto renal enenhum caso de morte foi relatado em conseqüência deste tipo de CCR.

$M$ ais recentemente, vários pacientes com CCR em enxerto renal foram tratados com crioablação percutânea, ${ }^{15}$ nefrectomia parcial ${ }^{2,4,10,11}$ ou mesmo com nodulectomia ${ }^{14}$ e manutenção da terapia imunossupressora e não houve caso de recorrência relatada (em acompanhamentos de um a cinco anos). Estes relatos tendem a demonstrar que o CCR localizado em um enxerto renal pode ser tratado de forma segura e efetiva com nef rectomia parcial, com um mínimo potencial de recorrência ou doença metastática.

\begin{abstract}
Introduction and dojective: The cystic renal disease has been reported in patients with final stage of renal disease treated by dialysis or being submitted to renal transplantation. The renal tumor incidence in patients with acquired renal cystic disease submitted to hemodialysis is high. Recent reports have related renal cell carcinoma occurred in native kidneys with acquired cystic disease submitted to transplant. This paper has as purpose to describe a case of renal carcinoma in a renal graft. Method and Casereport: We are reporting a case of renal cell carcinoma developed in a rejected allograft from a living related donor with acquired renal cystic disease 14 years (169 months) after transplantation, successfully treated by graft nephrectomy. Condusions: Patients submitted to transplant have an increased incidence of malignancy, compared to the general population. Including our case, 24 de novo cases of renal neoplasms developed in renal allografts are reported, and to the best of our knowledge, this is the third reported case of renal cell carcinoma associated with acquired renal cystic disease in an allograft kidney.
\end{abstract}

Key words: K idney Transplantation; Transplant; K idney Neoplasms; Cyclosporine; Postoperative Complications; K idney Diseases, Cystic.

\section{REFERÊNCIAS}

1. Dlugosz BA, Bretan PN, Jr., Novick AC, et al. Causes of death in kidney transplant recipients: 1970 to present. Transplant Proc 1989; 21 (1 Pt 2): 2168.

2. Feldman JD, Jacobs SC. Late development of renal carcinoma in allograft kidney. J Urol 1992; 148 (2 Pt 1): 395.

3. Penn I. Donor transmitted disease: cancer. Transplant Proc 1991; 23 (5): 2629.

4. Thomalla JV. Renal cell carcinoma in a renal allograft successful treatment with 5 year follow-up. Clinical Medicine \& Research 2004; 2 (3).

5. Kawamura K, Ikeda R, Suzuki K. [Acquired renal cystic disease]. Hinyokika Kiyo 2000; 46 (9): 651

6. Fukatsu T, Nishikawa A, Yonemura S, et al. [Two cases of renal cell carcinoma arising in the native kidney following renal transplantation--clinical study and review of 26 cases reported in Japan]. Hinyokika Kiyo 2004; 50 (2): 81

7. Claudon M, Panescu V, Le Chaffotec L, et al. Primary adenocarcinoma of the renal transplant. Nephrol Dial Transplant 1998; 13 (10): 2667.

8. Williams JC, Merguerian PA, Schned AR, Morrison PM. Acquired renal cystic disease and renal cell carcinoma in an allograft kidney. J Urol 1995; 153 (2): 395.
9. Ghasemian SR, Guleria AS, Light JA, Sasaki TM. Multicentric renal cell carcinoma in a transplanted kidney. Transplantation 1997; 64 (8): 1205

10. Lamb GW, Baxter GM, Rodger RS, Aitchison M. Partial nephrectomy used to treat renal cell carcinoma arising in a live donor transplant kidney. Urol Res 2004; 32 (2): 89.

11. Siebels M, Theodorakis J, Liedl B, Schneede P, Hofstetter A. Large de novo renal cell carcinoma in a 10-year-old transplanted kidney: successful organ-preserving therapy. Transplantation 2000; 69 (4): 677.

12. Lien YH, Hunt KR, Siskind MS, Zukoski C. Association of cyclosporin A with acquired cystic kidney disease of the native kidneys in renal transplant recipients. Kidney Int 1993; 44 (3): 613.

13. Vogt P, Frei U, Repp H, Bunzendahl H, Oldhafer K, Pichlmayr R. Malignant tumours in renal transplant recipients receiving cyclosporin: survey of 598 first-kidney transplantations. Nephrol Dial Transplant 1990; 5 (4): 282.

14. Park KI, Inoue H, Kim CJ, Tomoyoshi T. Nephron sparing surgery for de novo renal cell carcinoma in an allograft kidney: a case report. Int J Urol 1997; 4 (6): 611.

15. Shingleton WB, Sewell PE. Percutaneous cryoablation of renal cell carcinoma in a transplanted kidney. BJU Int 2002; 90 (1): 137. 